\title{
Specimen Geometry Effect on the Deformation Mechanisms of Polypropylene-Based Composites Under Impact Loading at Different Temperatures
}

\author{
K. Wang ${ }^{1}$ (D) $\cdot$ N. Bahlouli ${ }^{2} \cdot$ R. Matadi Boumbimba ${ }^{3} \cdot$ F. Addiego ${ }^{4} \cdot$ \\ Y. Rémond ${ }^{2}$
}

Received: 31 October 2015/Accepted: 18 January 2016/Published online: 25 January 2016

(C) Society for Experimental Mechanics, Inc 2016

\begin{abstract}
Dynamic behaviors of polypropylene (PP), PPethylene propylene rubber (PP-EPR) and PP-nanoclay (PP-Nanocor) composites were studied by using split Hopkinson pressure bar at different temperatures and under different strain rates. Samples with two different geometries and with or without petroleum jelly lubricant were tested under identical testing conditions to compare the dynamic responses with underlying deformation mechanisms. For all the test temperatures and strain rates, the dynamic responses of neat PP and PP-Nanocor showed post-yield strain-softening, whereas those of PP-EPR showed strain-hardening after the yield point. PP-Nanocor showed more strain-softening compared with neat PP at room temperature due to the more important localized shearing deformation at the nanofiller/matrix interfaces. Friction between the sample and the bars affected the dynamic response of the materials at room temperature as well as high temperatures seen as differences in behavior between the dynamic behaviors of the non-lubricated thin samples and the non-lubricated thick samples under the
\end{abstract}

K. Wang

kwang@qf.org.qa

1 Qatar Environment and Energy Research Institute (QEERI), Hamad Bin Khalifa University (HBKU), Qatar Foundation, PO Box 5825, Doha, Qatar

2 ICube Laboratory, University of Strasbourg/CNRS, 2 Rue Boussingault, 67000 Strasbourg, France

3 Laboratory of Mechanics, Biomechanics, Polymers and Structures, National Engineering School of Metz, 1 route d'Ars Laquenexy, 57078 Metz, France

4 Department of Materials Research and Technology (MRT), Luxembourg Institute of Science and Technology (LIST), 4940 Hautcharage, Luxembourg same testing conditions. At room temperature and without lubrication, the thicker specimens of neat PP and PPNanocor failed during dynamic testing due to the barrelinginduced crack that propagated in the specimen and led to the formation of a peripheral fragment. Although petroleum jelly provided a satisfactory lubrication condition for both neat PP and PP-based composites at room temperature and at high temperatures, by reducing the friction effect on the yield behavior, the lubrication did not have a significant effect on the post-yield behavior of neat PP and PPNanocor, particularly for the room temperature testing and with the thick specimens.

Keywords Polypropylene - Impact - Temperature · Deformation mechanism $\cdot$ Composites

\section{Introduction}

Research in the area of dynamic behavior of polymeric materials has been gradually growing in recent years. In fact, neat polymeric materials and polymer-based composites are widely used in engineering applications such as automotive and aerospace industries where high loading rates and wide range of temperatures are involved. In order to investigate the dynamic behavior of materials, Kolsky bars, also named split Hopkinson bars, are commonly used to achieve a strain rate larger than $10^{2} \mathrm{~s}^{-1}[1,2]$.

In the literature, different studies reported that the dynamic behavior of a given polymeric material is not always in good agreement even though the experimental conditions (temperature and strain rate) are similar [3]. On the one hand, the properties of the same polymer are often dependent on the grade and batch types. On the other hand, unlike quasi-static testing methods, dynamic testing in 
Hopkinson bars is not controlled by feed-back systems. Therefore, using this experimental method, one needs to pay more attention to obtain the intrinsic behavior of polymeric materials [4-6].

Furthermore, no specific standard exists for the dynamic testing conducted with Hopkinson bars technique. Only some recommendations are provided in the literature $[1,2]$. Thus, different sample geometries have been used. For instance, in the case of compression, the specimens with diameter to length ratios $(D / L)$ less than 2 were chosen by Rietsch et al. [7], Guo et al. [8] and Furmanski et al. [9]. The specimens with moderate $D / L$ ratios from 2 to 3 were tested by Lee et al. [10], Segreti et al. [11], Wang et al. [12-14] and Matadi et al. [15]. In contrast, Pessey et al. [16]. used the specimens with $D / L$ ratio close to 5 .

Some experimental results show that the mechanical responses of a wide range of polymers and polymer composites are strongly sensitive to testing temperature and strain rate [17, 18]. Yield stresses obtained by using Hopkinson bars are significantly affected by sample size [19-21]. Therefore, an analysis of the sample size effect on the experimental measurements of the properties by using Hopkinson bars technique are necessary for obtaining accurate quantified behaviors of polymers and polymer composites.

Few existing works have addressed the sample size effect on the impact properties of amorphous [22, 23] and semi-crystalline polymers $[24,25]$ measured using Hopkinson bars technique. In this, most of the investigations were performed at room temperature $[3,4,19,20,26]$, except Trautmann et al. [22] who analyzed this effect at a cryogenic temperature. Among these studies, attention was usually focused on the yield behavior of the materials. To the best of our knowledge, no investigation of sample size effect on the deformation mechanisms of polypropylene (PP)-based composites have been reported. We note that these PP-based materials represent the second most important thermoplastic in term of market with a high annual growth rate. The aim of our work is to investigate the filler and sample size effects on the results obtained by using split Hopkinson pressure bar (SHPB) technique at different temperatures with and without lubricant. The materials tested in this study are neat PP and PP-based composites which are generally used for the manufacturing of bumpers in automotive industries.

\section{Experimental Technique and Sample Preparation}

\section{Split Hopkinson Pressure Bar Technique}

A typical SHPB set-up (Fig. 1) is an apparatus which consists of a striker bar, an incident bar and a transmitted bar. The incident and the transmitted bars of our SHPB are made of 316L steel with lengths of $3 \mathrm{~m}$ and a diameter of $22 \mathrm{~mm}$. Strikers 0.5 and $1 \mathrm{~m}$ in length are made of the same steel. The strain gages are glued on the middle of the incident and the transmitted bars at a distance of $1.5 \mathrm{~m}$ from the interface of specimen and bars. A furnace with two symmetrical resistance heaters is installed for hightemperature testing.

Cylindrical specimens are sandwiched between the incident bar and the transmitted bar to determine their dynamic responses under compression. The striker is used to generate a longitudinal compressive wave. Once this compressive wave reaches the incident bar, strain gages cemented on this bar can record an incident wave $\varepsilon_{I}(t)$. The difference in the mechanical impedances at the interface between the incident bar and the specimen results in the fact that a part of the incident wave reflects back along the incident bar while the other part passes through the specimen and then into the transmitted bar. The reflected wave $\varepsilon_{R}(t)$ is measured by the same strain gages cemented on the incident bar. The transmitted wave $\varepsilon_{T}(t)$ can be obtained by the same type of strain gages glued on the transmitted bar (Fig. 2). In addition, velocity sensor based on two laser beams is used to measure the velocity of the striker.

According to the classical elastic wave propagation theory, when the stress and strain fields are uniform in the specimen, the nominal stress $\left(\sigma_{n}\right)$, the nominal strain $\left(\varepsilon_{n}\right)$ and the nominal strain rate $\left(\dot{\varepsilon}_{n}\right)$ of the tested materials can be computed by the following expressions [1]:

$$
\begin{aligned}
& \dot{\varepsilon}_{n}=\frac{2 C_{b}}{L} \varepsilon_{R}(t) \\
& \varepsilon_{n}=\frac{2 C_{b}}{L} \int \varepsilon_{R}(t) d t \\
& \sigma_{n}=E\left(\frac{A}{A_{s}}\right) \varepsilon_{T}(T)
\end{aligned}
$$

Here, $C_{b}$ is the elastic wave speed in the incident and the transmitted bars (bars are made of the same materials); $E$ is the Young's modulus of the bars; $L$ represents the initial
Fig. 1 Schematic representation of a typical compression split Hopkinson pressure bar

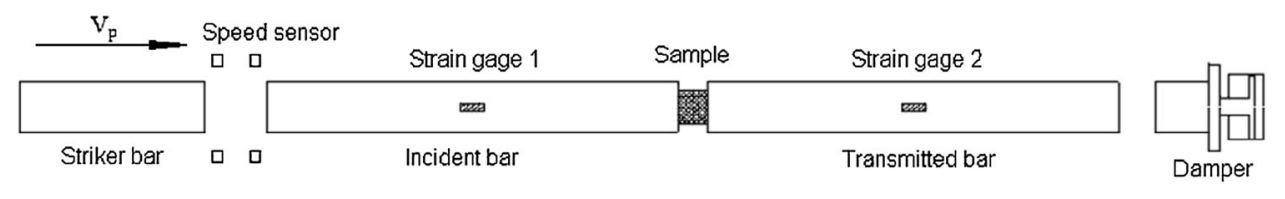




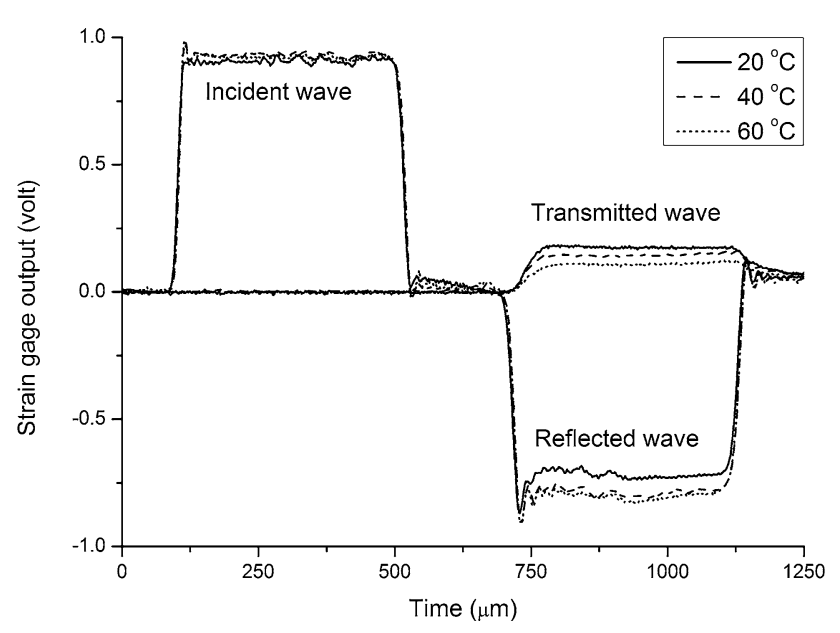

Fig. 2 Incident, reflected and transmitted waves obtained from the SHPB experimental setup for petroleum lubricated neat PP at different temperatures and at a strain rate of $1247 \mathrm{~s}^{-1}$

thickness of specimen; $A$ and $A_{s}$ are the cross sectional area of the bars and the specimen, respectively. The engineering stress and strain measurements can be used to derive the true ones (with the subscript $t$ ) using the following equations [27]:

$\dot{\varepsilon}_{t}(t)=\frac{\dot{\varepsilon}_{n}(t)}{1-\varepsilon_{n}(t)}$

$\varepsilon_{t}(t)=-\ln \left(1-\varepsilon_{n}(t)\right)$

$\sigma_{t}(t)=\sigma_{n}(t) \exp \left(-2 v \varepsilon_{t}(t)\right)$

These equations are written for compression when strains are taken positive. Equation (6) is derivated from $\sigma_{t}(t)=\sigma_{n}(t)\left(1-\varepsilon_{n}(t)\right)^{2 v}$, where $v$ is the Poisson's ratio. For an incompressible plastic material, this Poisson's ratio is equal to 0.5 . In this work, a value of $v=0.4$ was calculated by using the sample geometry after dynamic test.

During the dynamic test, an equilibration parameter, $R(t)$, can be used to evaluate the force equilibration process through the following equation [28]:

$R(t)=\left|\frac{\Delta F(t)}{F_{m}}\right|=2\left|\frac{F_{\text {input }}-F_{\text {output }}}{F_{\text {input }}+F_{\text {output }}}\right|$

Here, the input force at the front end of incident bar and specimen, $F_{\text {input }}$, was calculated from the incident wave $\varepsilon_{I}(t)$ and the reflected wave $\varepsilon_{R}(t)\left(F_{\text {input }}=S_{b} E_{b}\left(\varepsilon_{I}(t)+\right.\right.$ $\left.\varepsilon_{R}(t)\right)$, where $S_{b}$ is the cross-section area of the bar, $E_{b}$ is the Young's modulus of the bars). The output force at the back end of specimen and transmission bar was calculated from the transmitted wave $\varepsilon_{T}(t)\left(F_{\text {output }}=S_{b} E_{b} \varepsilon_{T}(t)\right)[4,21]$.

\section{Assumption of Split Hopkinson Pressure Bar}

The split Hopkinson pressure bar analysis is based on four major simplifying assumptions [29, 30]: (1) The waves in elastic bars propagate in one-dimension; (2) In the axial direction, the stress and strain fields in the specimen are uniform; (3) The inertia effect on the specimen is neglected; (4) The friction effect on the interface between the specimen and bars is neglected.

The first assumption is generally accepted when the incident wave is much longer than the length of specimens [30, 31].

Applying the second assumption, Eq. (1) becomes correct only when the stress and strain fields are uniform in the specimen. However, it is not valid at the beginning of the impact test. Actually, when the first wave reaches the interface of the specimen and the incident bar, the interface of the specimen and the transmitted bar is not yet loaded. For a given material, the duration of the wave propagation through the specimen depends upon the sample thickness. Therefore, this effect is even more severe for thick samples [32]. In order to minimize this effect, thin specimens are more acceptable [4, 33, 34].

During a high strain rate compressive test, besides the axial particle velocity of the specimen, both radial and tangential particle velocities achieve high values. The resulting necessary accelerations produce high compressive stresses in all three directions. Therefore, the hydrostatic part of the stress tensor is large. Consequently, the specimen remains constrained, showing greater apparent resistance to deformation than that for an ideal one-dimensional stress compressive test [35]. Even though the inertia effect is one of the major sources of error in impact testing [36, 37], some authors report that this effect can be minimized if small specimens are used at high rates [24, 38]. Song et al. [4] noted that the induced inertia just led to a small increase of the intrinsic yield stress of the material. Trautmann et al. [22] showed that the inertial stresses of PC were less than $0.2 \mathrm{MPa}$ for the thin specimen $(0.5 \mathrm{~mm})$ and less than $1 \mathrm{MPa}$ for the thick specimens $(5 \mathrm{~mm})$ during the acceleration phase under a strain rate of $2500 \mathrm{~s}^{-1}$. Thus, the inertia effect on the measured yield stresses can be neglected when thin specimens are used.

Friction is considered to be the largest source of error in the SHPB technique [39]. During high strain rate compression tests, friction between the surfaces of the sample and the bars tends to constrain the lateral flow of the sample. This constraint generates a hydrostatic stress that is superimposed upon the axial stress, resulting in a three dimensional stress state. For this reason, the measured mechanical response of tested materials tends to exaggerate their real behavior [39]. Moreover, this error is more evident for thin specimens which results in high measured yield stresses [35]. Different lubricant layers have been used to reduce the interfacial friction, such as silicone grease [38], oleamide [3], stearamide [3], petroleum jelly $[3,19,22,38,40]$, molybdenum disulphide $[22,30,41]$ and polytetrafluoroethylene [22]. Petroleum jelly is a 
suitable lubricant for polymeric materials which can effectively reduce the frictional effect on SHPB testing at low temperature $\left(-60^{\circ} \mathrm{C}\right)$ and at room temperature $[3,22$, 26, 33, 38].

As discussed above, thin specimens are more acceptable to minimize the effects of the non-uniform stress field and inertia of specimens in SHPB tests. However, thin specimens tend to increase the frictional stresses.

\section{Materials and Experimentations}

Three different materials were studied. The first one is a neat PP referenced as Moplen HP500 N (highly isotactic grade produced by Lyondellbasell, Netherlands). This neat PP has a glass transition temperature of $12.2{ }^{\circ} \mathrm{C}$ and a crystallinity degree of $49.2 \%$ [42]. The second one is an ethylene propylene rubber (EPR) filled PP (referenced as SABIC, Saudi Arabia, grade 108MF97, with $22 \mathrm{wt} \%$ EPR) [43]. The third one is a home mixed PP (Moplen HP500 N, Lyondellbasell, Netherlands) based nanocomposite with $6 \mathrm{wt} \%$ of organoclay [44]. In the following, these three materials are denoted by Neat PP, PP-EPR and PP-Nanocor. The pellets of these three materials were first dried in an air-circulating oven for $60 \mathrm{~min}$ at $80^{\circ} \mathrm{C}$, and then injection molded to produce. Cylindrical specimens with diameters of $8 \mathrm{~mm}$ and two different thicknesses of 3 and $6 \mathrm{~mm}$ were cut from the injection-molded plates using a die cutter.

In order to have the same experimental environment for each specimen, at each change of temperature, the furnace was first held at the required temperature without specimen for half an hour to obtain a uniform temperature field [12]. Then the specimen was inserted into the furnace for $15 \mathrm{~min}$ to produce thermal equilibration. Dynamic testing was carried out at three temperatures (20 (room temperature), 40 and $\left.60{ }^{\circ} \mathrm{C}\right)$, and under two strain rates $\left(\dot{\varepsilon}_{1}=1247 \pm 3.5\right.$ and $\dot{\varepsilon}_{2}=2247 \pm 4.8 \% \mathrm{~s}^{-1}$ ). Note that the strain rates were obtained from the true strain rate versus true strain curves with the same strain level for the yield stress. For current study, the heated bars' end inside the furnace may result in a non-uniform distribution of temperature at the end of bars disturbing the propagation of elastic waves, and consequently inducing some errors while using the usual processing of the SHPB. Figure 2 shows the incident, reflected and transmitted waves obtained from the SHPB experimental setup for petroleum lubricated neat PP at different temperatures and at a strain rate of $1247 \mathrm{~s}^{-1}$. In Fig. 2, the incident waves for the three testing temperatures have a good superposition indicating that the non-uniform distribution of temperature at the end of bars had limited effect on the elastic wave propagation. In addition, five experiments per condition were performed, which allows us to determine averaged values for each condition.

\section{Results and Discussions}

\section{Tests Without Lubrication}

Figure 3 shows the evolution of the equilibration parameter $R(t)$, as a function of time for the $3 \mathrm{~mm}$ thick petroleum lubricated neat $\mathrm{PP}$ at different temperatures and at $\dot{\varepsilon}_{1}=1247 \mathrm{~s}^{-1}$, with a sampling time on the oscilloscope of $1 \mu \mathrm{s}$. It indicates that the specimens could be considered in force equilibrium roughly $50 \mu$ s after the initial dynamic loading for all the three testing temperatures. Note that a force equilibrium time of about $50 \mu \mathrm{s}$ was found for all investigated PP-based composites at both strain rates and at three temperatures.

Experimental true-stress versus true-strain curves under uniaxial compressive loading for $8 \mathrm{~mm}$ diameter neat PP, PP-Nanocor and PP-EPR samples are plotted in Figs. 4, 5 and 6 . The samples have two different thicknesses $(3 \mathrm{~mm}$ and $6 \mathrm{~mm}$ ) and the mechanical testing was conducted at three temperatures and under two strain rates. These samples were tested without lubricant. In Figs. 4, 5 and 6, the yield stress of PP-Nanocor is higher than those of neat PP under the same testing conditions. This is due to the presence of rigid fillers in PP-Nanocor [12]. PP-EPR has the lowest yield stress compared to those of neat PP and $\mathrm{PP}-\mathrm{Nanocor}$ under the same testing conditions. Even though the PP matrix of PP-EPR is probably different from neat PP, the main reason of the lower yield stress of PPEPR is probably due to the presence of the soft impact modifier of EPR [45]. In Figs. 4, 5 and 6, for both sample thicknesses, the experimental results clearly show the sensitivity of all tested materials to the test temperature and strain rate [46]. The high test temperature decreases the yield stress and the flow stress of the materials whereas the

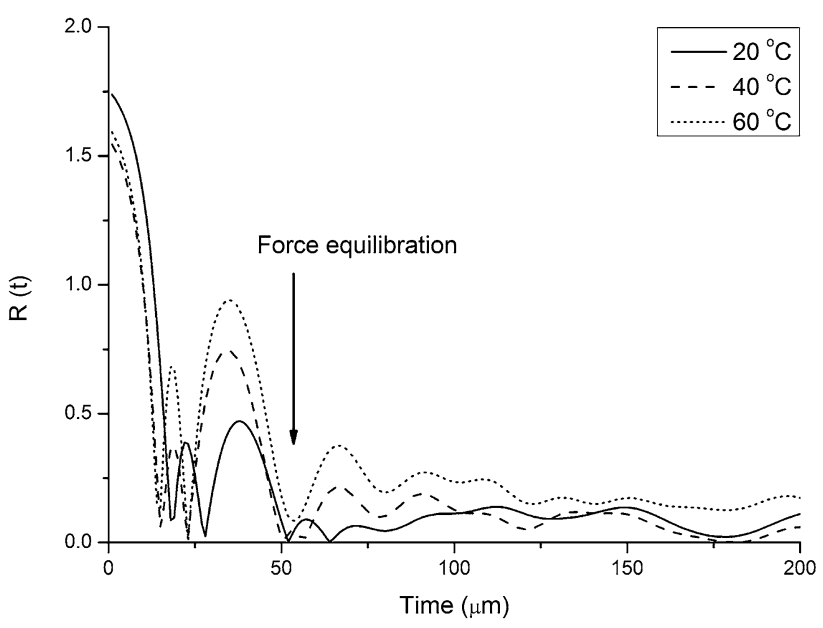

Fig. 3 Dynamic force equilibration processes in petroleum lubricated neat PP with a thickness of $3 \mathrm{~mm}$ and a diameter of $8 \mathrm{~mm}$ at different temperatures and at $\dot{\varepsilon}_{1}=1247 \pm 3.5 \% \mathrm{~s}^{-1}$ 

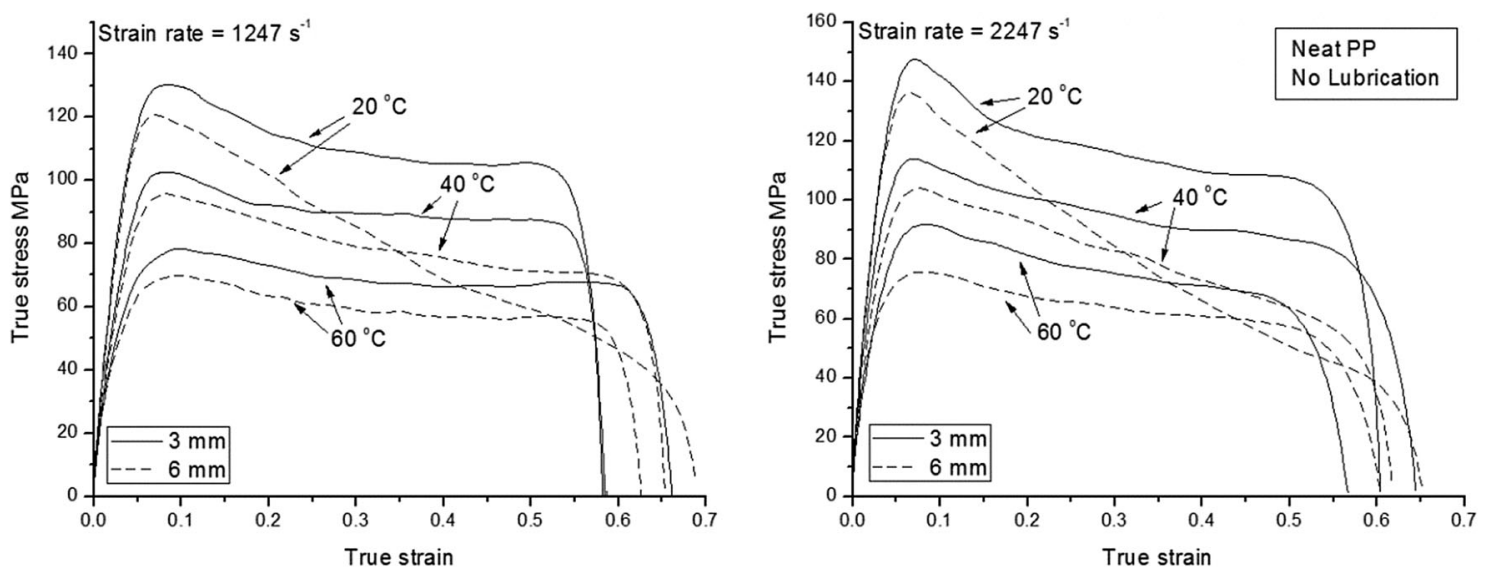

Fig. 4 Experimental true-stress versus true-strain curves under uniaxial compression loading for 8 mm diameter neat PP samples of two different thicknesses at three temperatures and under two strain rates, no lubrication
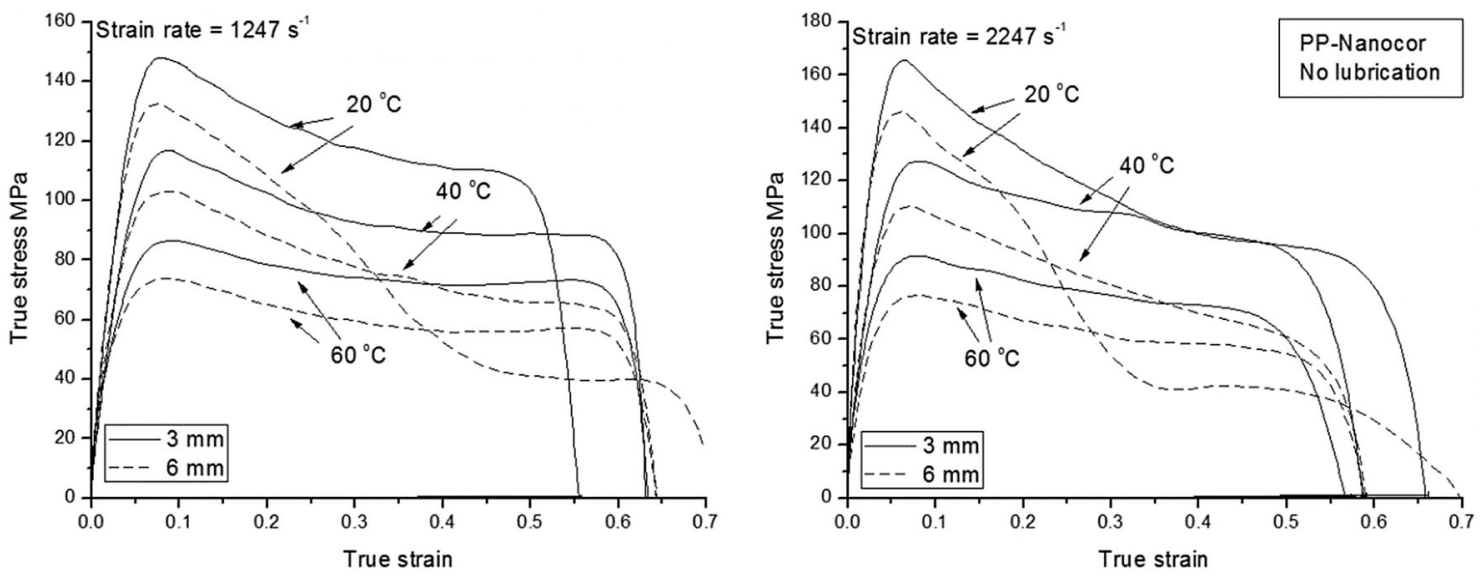

Fig. 5 Experimental true-stress versus true-strain curves under uniaxial compression loading for $8 \mathrm{~mm}$ diameter PP-Nanocor samples of two different thicknesses at three temperatures and under two strain rates, no lubrication
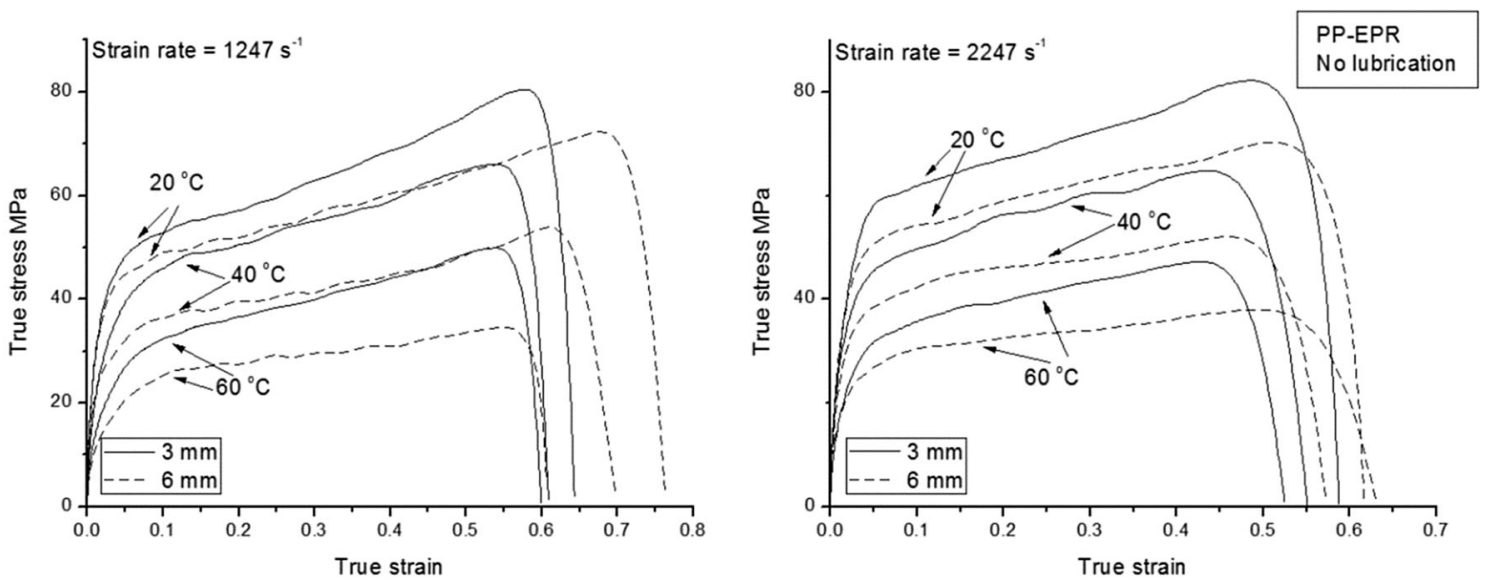

Fig. 6 Experimental true-stress versus true-strain curves under uniaxial compression loading for 8 mm diameter PP-EPR samples of two different thicknesses at three temperatures and under two strain rates, no lubrication 
high strain rate leads to an increase in the yield and flow stresses. In addition, the dynamic responses of neat PP and PP-Nanocor show post yield strain softening, whereas the dynamic responses of PP-EPR show strain hardening after the yield point for both strain rates and for the three temperatures. Indeed, when polymers are subjected to high loading rates, the effects of strain hardening, strain rate and temperature sensitivity play important roles in the behavior of materials [47]. The dynamic behavior of materials is based on the opposing tendency of materials to strengthen at high strain rates and to soften with the temperature increase produced by adiabatic loading conditions [48, 49].

The ratio $\beta$ (the fraction of plastic work converted to heat for plastic materials during high strain rate deformation) ranges from 0.4 to 1 [50-52]. For our materials, taking a density of $900 \mathrm{~kg} / \mathrm{m}^{3}$ and a heat capacity of $1925 \mathrm{~J} / \mathrm{K}$ for neat PP and PP-based composites, the rise in temperature, $\Delta T$, within the specimen can be calculated by the plastic work ( $W=\int_{0}^{\varepsilon} \sigma d \varepsilon$ ) and the heat conversion ratio (dissipated energy $Q=\beta \cdot W=\rho \cdot C p \cdot \Delta T$, where $\rho$ is the material's density, $C p$ is the heat capacity of the material). At room temperature and at $\dot{\varepsilon}_{2}=2247 \mathrm{~s}^{-1}$, by assuming the $\beta$ is 1 (all the plastic work till to the maximum strain is converted into heat), temperature rises of 41 and $27{ }^{\circ} \mathrm{C}$ were estimated for 3 and $6 \mathrm{~mm}$ thick neat PP, respectively, and 42 and $24{ }^{\circ} \mathrm{C}$ for 3 and $6 \mathrm{~mm}$ thick PP-Nanocor, respectively. For $3 \mathrm{~mm}$ and $6 \mathrm{~mm}$ thick PP-EPR, temperature rises of 24 and $21{ }^{\circ} \mathrm{C}$ were estimated, respectively.

The post-yield softening of neat PP and PP-Nanocor is probably due to the failure induced by adiabatic shear banding which overcomes the effect of high strain rate strengthening [53]. In addition, PP-Nanocor showed more post-yield strain softening, particularly for room temperature testing, compared with neat PP for both thickness samples and both strain rates. This greater degree of strain softening can be attributed to localized shearing deformation in the matrix as well as at the nanofiller/matrix interfaces. For higher testing temperatures, the lower post yield strain softening effects are probably due to the decrease of internal interaction forces of the materials, leading to a decrease of internal friction. Similar results were reported by Williamson et al. [54] on temperature-time response of a highly-filled polymer composite. They found that changing polymer sample temperature would bring about internal stresses via different thermal contraction and consequently have different time-temperature sensitivities. For PP-EPR, the failure is mainly associated with a craze-like damage, identified as a highly shear localized type of dilatational bands. These are formed when shear bands connect cavitated EPR particles [55, 56]. For blends with good rubber/matrix adhesion, after cavitation a rubber layer forms which is strongly attached to the inner surface of the newly formed void [56]. This rubber layer could stabilize dilatational band propagation by delaying strain localization and premature failure of the ligaments [56]. This may probably result in post-yield hardening of $\mathrm{PP}-$ EPR.

At room temperature, the true stress-true strain curves of the two different thicknesses exhibit clear differences for all materials. Thin specimens $(3 \mathrm{~mm})$ show higher stress states due to friction effects. This effect can be explained by the analysis proposed by Siebel $[57,58]$. According to this, the measured yield stress $(P)$ of the material can be theoretically estimated by Eq. (8) below:

$P=\left(1+\frac{\mu D}{3 L}\right) \sigma_{y}$

Here, $\mu$ is the coefficient of friction, $D$ and $L$ are the diameter and thickness of the specimen, respectively and $\sigma_{y}$ represents the intrinsic yield stress of the material. In this equation, if $\mu$ is constant for a given material, the aspect ratio, $D / L$, of the specimen is the only parameter that could affect the measured yield stress of the material. Therefore, according to Eq. (8), thinner specimens produce higher measured yield stresses for the same specimen diameter. This can be used to explain the existence of gaps between the experimental curves for two different thickness specimens. At high temperatures $\left(40\right.$ and $\left.60^{\circ} \mathrm{C}\right)$, the mechanical response decreases for all the materials compared that at room temperature. However, the true stresstrue strain curves for two different thickness specimens show that similar frictional effects still exist in the impact tests even at high temperatures.

Besides, the mechanical response of the thick specimens $(6 \mathrm{~mm})$ shows a rapid decrease of the flow stress after the yield point in comparison with the thin specimens $(3 \mathrm{~mm})$ for neat PP and PP-Nanocor (see Figs. 4, 5). Similar results of the rapid decrease of the stress in thick specimens have been reported for an aluminum alloy [48]. The rapid decrease of the stress after the yield point in thick specimens may be attributed to the barreling effect [59]. Figure 7 shows optical micrographs for $3 \mathrm{~mm}$ and $6 \mathrm{~mm}$ thick neat PP specimens after dynamic testing at room temperature and at $\dot{\varepsilon}_{2}=2247 \mathrm{~s}^{-1}$. The thick neat PP showed more important peripheral crack fragments than the thin one after dynamic test. This is probably due to the barreling effect induced crack that propagated in the specimen and led to the materials peripheral fragment. Similar longitudinal and diagonal facture planes were observed by Kudo and Aoi [60, 61] at the equatorial free surfaces of a medium-carbon steel cylindrical specimen in upsetting. We note that the thick PP-Nanocor had similar peripheral fragments after dynamic testing. In order to 
Fig. 7 Optical microscope images for $3 \mathrm{~mm}$ and $6 \mathrm{~mm}$ neat PP specimens after dynamic test performed at room temperature and at $\dot{\varepsilon}_{2}=2247 \mathrm{~s}^{-1}$
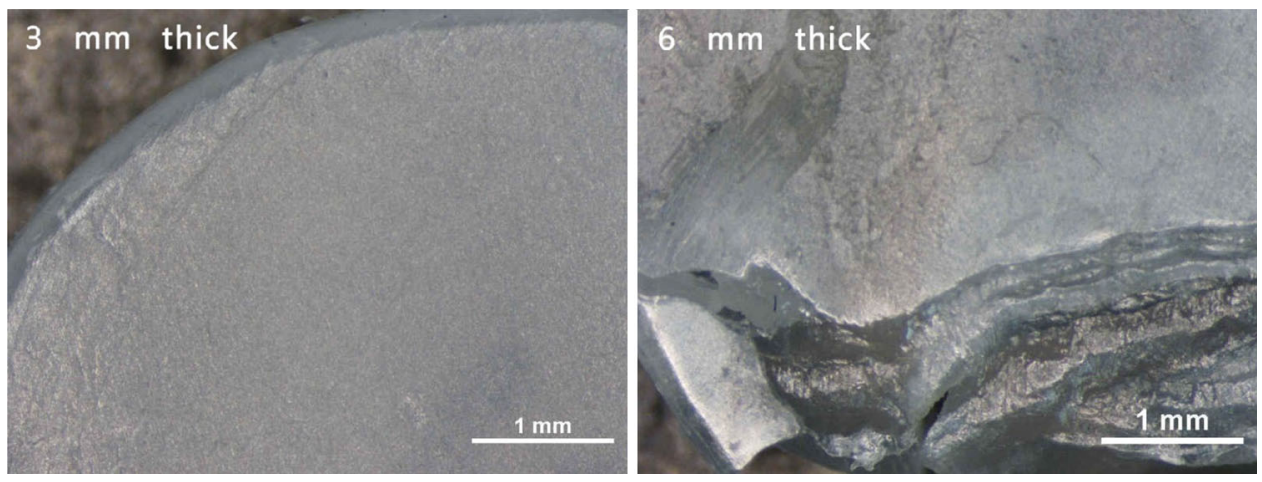

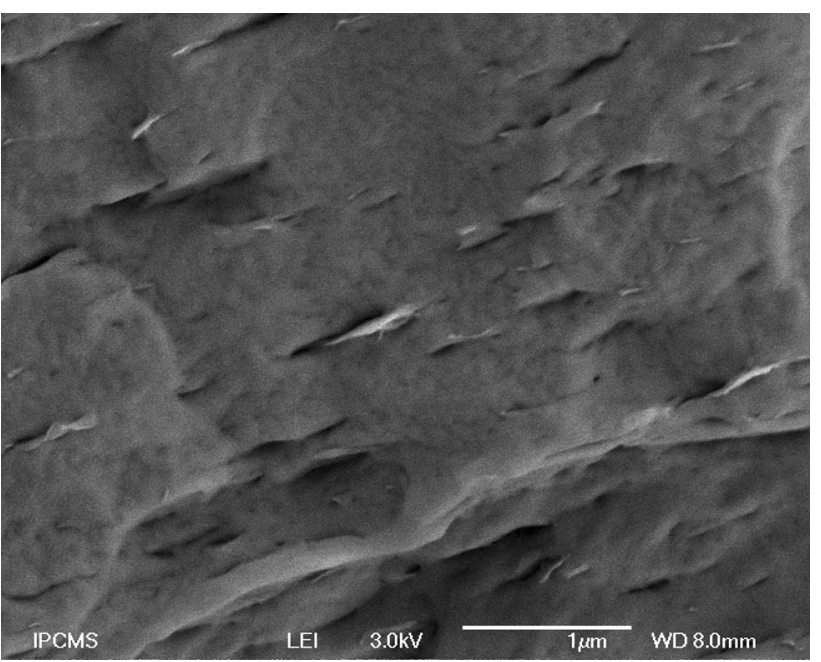

Fig. 8 Scanning electron microscope (SEM) image of the fracture surface of thick PP-Nanocor after dynamic testing at room temperature and at $\dot{\varepsilon}_{2}=2247 \mathrm{~s}^{-1}$

analyze the damage mechanisms, a scanning electron microscope (SEM) have been used. Figure 8 shows the fractured surface of thick PP-Nanocor after a dynamic test performed at room temperature and at $\dot{\varepsilon}_{2}=2247 \mathrm{~s}^{-1}$. Even though the thick PP-Nanocor underwent high strain rate dynamic compression, acceptable adhesion between the fillers and the matrix (Fig. 8) could be observed. This observation allows us to conclude that the main failure of the material occurred in the matrix by crack.

Strain softening reduces as the temperature of the test is increased, vanishing for the test at $60{ }^{\circ} \mathrm{C}$. At $60^{\circ} \mathrm{C}$, the experimental curves of neat PP and PP-Nanocor for both thickness samples show similar stress falls after the yield point which can be mainly attributed to softening of the material at high temperatures. However, the experimental responses of thick specimens of PP-EPR (see Fig. 6) do not exhibit a similar rapid decrease after the yield point but rather strain hardening at all three temperatures. This is due to the presence of EPR which increases the critical strain energy release rate for crack propagation [62].

\section{Lubrication with Petroleum Jelly}

Petroleum jelly is a semi-solid low viscosity hydrocarbon with a low melting temperature. When used, petroleum jelly forms a thin film between the interface of the specimen and the bars acting as a lubricant. During impact testing, petroleum jelly lubricant provides a low sliding friction [22].

In Figs. 9, 10 and 11, the experimental true-stress versus true-strain curves under uniaxial compression loading for $8 \mathrm{~mm}$ diameter neat PP, PP-Nanocor and PP-EPR samples with two different thicknesses ( 3 and $6 \mathrm{~mm}$ ) at various temperatures and strain rates are plotted. All the samples were lubricated by petroleum jelly. These three figures show that the petroleum jelly effectively reduced the interfacial friction between the specimens and the bars seen as a reduction of the gaps between the curves for the two different thickness samples tested under the same conditions. The experimental room temperature curves of the two different thicknesses of neat PP and PP-Nanocor are very close up to the yield point. However, as for the nonlubricated samples, after the yield point, the curves of the thicker specimens show a similar rapid decrease compared to Figs. 4 and 5. By contrast, the experimental results for PP-EPR show practically identical curves for the two different thicknesses at all test temperatures and strain rates (see Fig. 11). If a specimen is well lubricated at all times and strains, the deformation should be uniform throughout the thickness under uniaxial loading. Thus, in the welllubricated case, there should be no significant barreling effect. For petroleum jelly- lubricated specimen, there may be a critical pressure to squeeze the petroleum jelly out from the interface between the specimen and the bars during the dynamic test. The loss of lubricant at this critical stress may result in an increase in the friction and consequently barreling of the specimen. This barreling effect may induce the crack, and then lead to the specimen peripheral fragments. For our investigation, a critical stress of about $70 \mathrm{MPa}$ was found to squeeze out the petroleum jelly during the dynamic tests (see Figs. 9, 10, 11). 

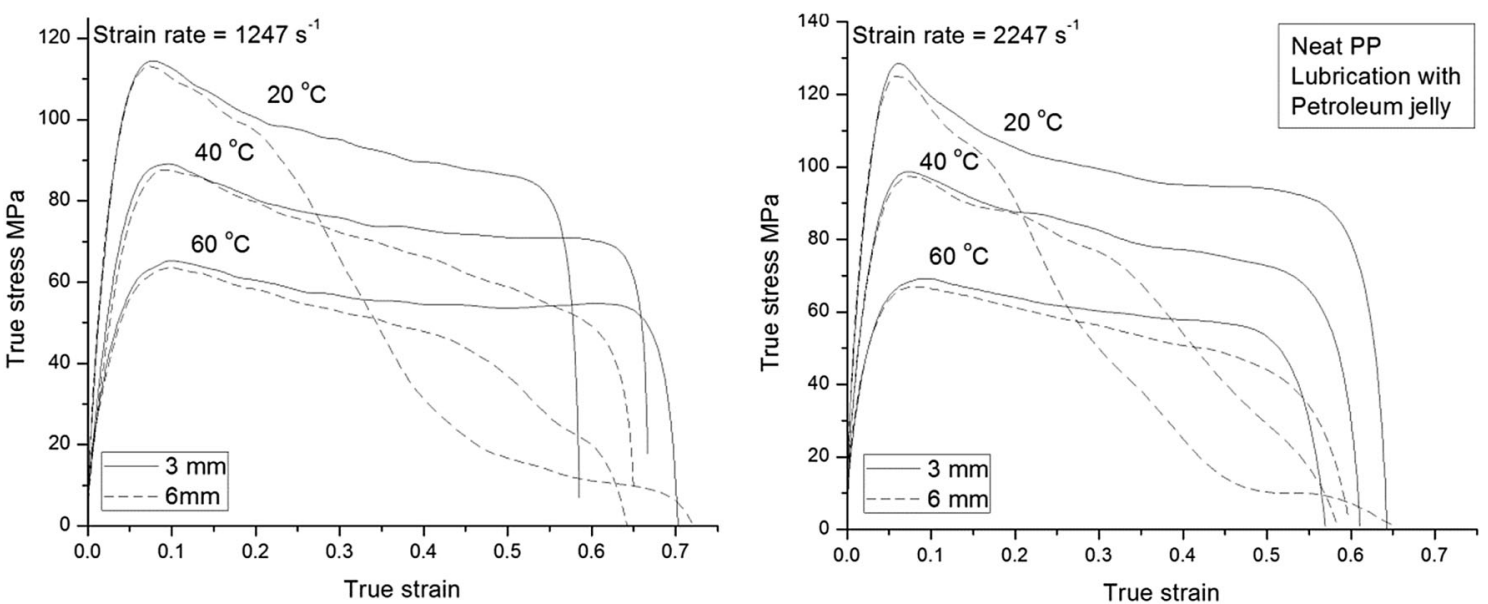

Fig. 9 Experimental true-stress versus true-strain curves under uniaxial compression loading for $8 \mathrm{~mm}$ diameter neat PP samples of two different thicknesses at three temperatures and under two strain rates, lubrication with petroleum jelly
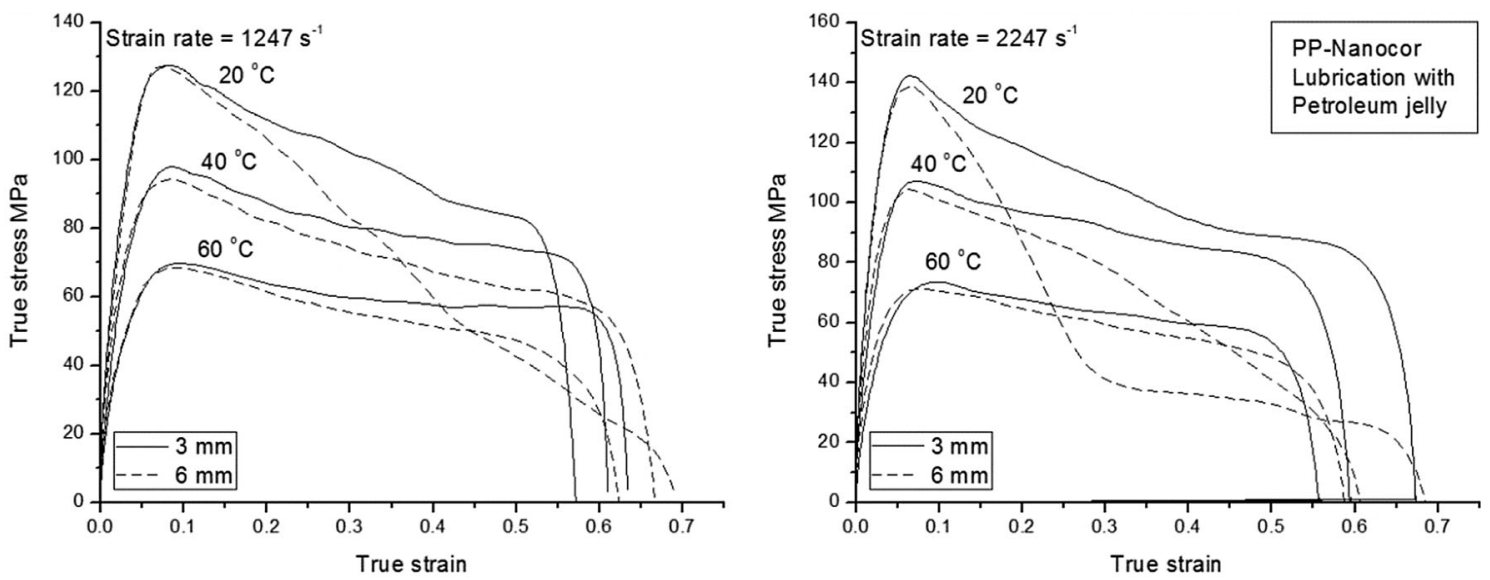

Fig. 10 Experimental true-stress versus true-strain curves under uniaxial compression loading for $8 \mathrm{~mm}$ diameter PP-Nanocor samples of two different thicknesses at three temperatures and under two strain rates, lubrication with petroleum jelly
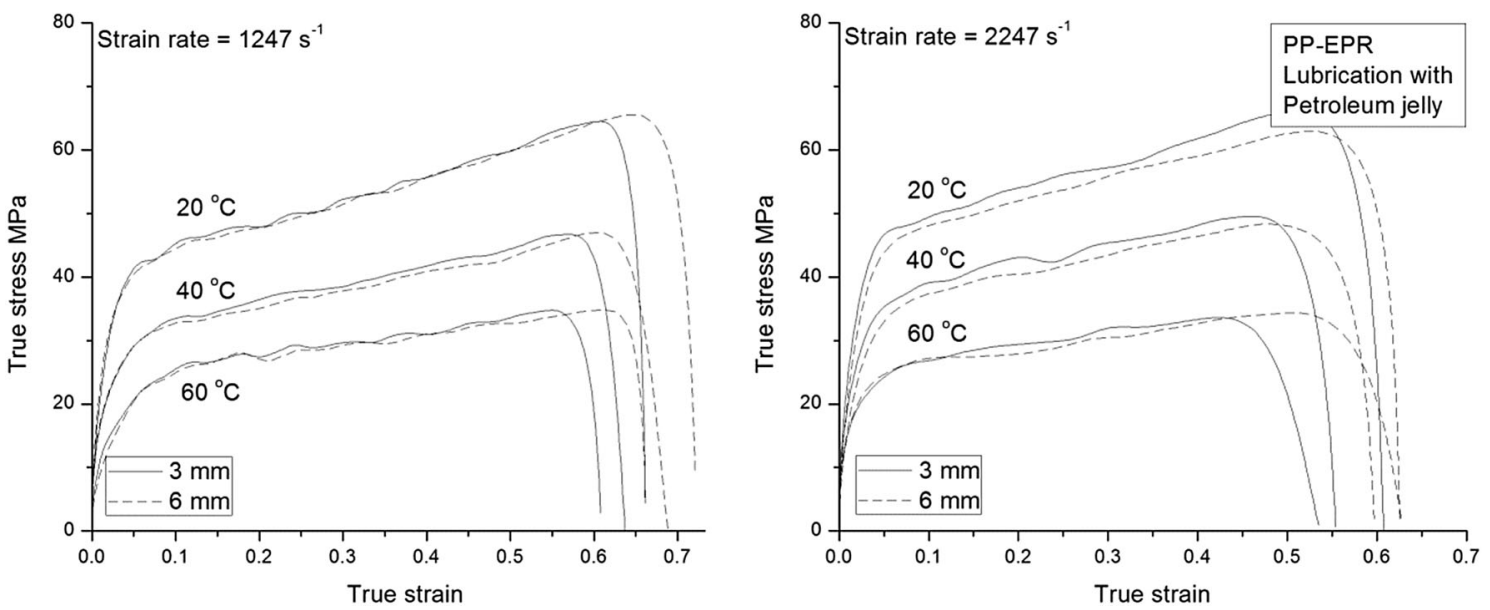

Fig. 11 Experimental true-stress versus true-strain curves under uniaxial compression loading for 8 mm diameter PP-EPR samples of two different thicknesses at three temperatures and under two strain rates, lubrication with petroleum jelly 


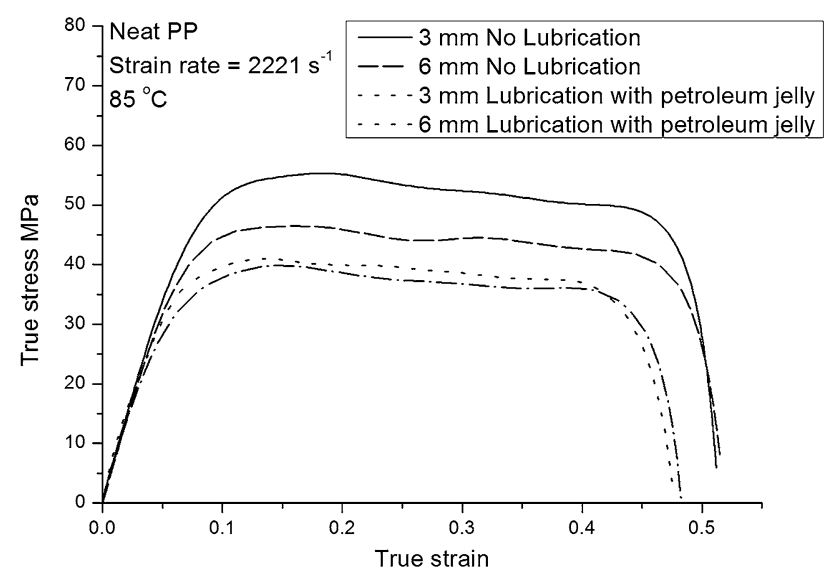

Fig. 12 Experimental true-stress versus true-strain curves under uniaxial compression loading for $8 \mathrm{~mm}$ diameter neat PP samples of two different thicknesses at $85{ }^{\circ} \mathrm{C}$ and at $\dot{\varepsilon}_{2}=2247 \pm 4.8 \% \mathrm{~s}^{-1}$, lubrication with/without petroleum jelly

Therefore, petroleum jelly did not affect the post yield behaviors observed in thick specimens of neat PP and PPNanocor at room temperature for both strain rates.

Petroleum jelly has a low melting temperature. In order to examine the lubrication effect of petroleum jelly on dynamic testing at a higher temperature, dynamic tests for neat PP at $85{ }^{\circ} \mathrm{C}$ and at $\dot{\varepsilon}_{2}=2247 \pm 4.8 \% \mathrm{~s}^{-1}$ were performed. Figure 12 shows experimental data for neat PP with two thicknesses, with or without petroleum jelly lubrication. Our experimental results indicated that petroleum jelly could effectively reduce the friction effect on the dynamic behavior of neat $\mathrm{PP}$ at $85^{\circ} \mathrm{C}$. When the petroleum jelly lubricated specimen was sandwiched between the incident bar and the transmitted bar, the spacing between the specimen and the bars was quite limited. During heating at $85{ }^{\circ} \mathrm{C}$, although petroleum jelly reached the melting point and became less viscous, it still stayed between the specimen and the bars. The less viscous petroleum jelly might continuously provide a valid test condition. Furthermore, we believe that $85{ }^{\circ} \mathrm{C}$ is the highest temperature at which the dynamic behavior of polymeric materials should be investigated for engineering applications.

\section{Conclusions}

In this study, a split Hopkinson pressure bar was used to investigate the dynamic behaviors of neat PP and PP-based composites. Dynamic testing was conducted at different temperatures and strain rates to study the dynamic responses of the materials to temperature and strain rate effects. Specimens with two different diameter/length ratios with or without petroleum jelly lubricant were tested under identical testing conditions to compare their dynamic properties with the underlying deformation mechanisms. It was found that the addition of the rigid organoclay increased the yield stress and the Young's modulus of the materials, whereas the addition of the soft ERP decreased the yield stress and the Young's modulus. Whatever sample thickness, the yield stress and the flow stress of the materials increased with increasing strain rate and with decreasing testing temperature. In addition, the dynamic responses of neat PP and PP-Nanocor showed post yield strain softening due to the localized shearing deformation in the matrix as well as at the nanofiller/matrix interfaces. The dynamic responses of PP-EPR showed strain hardening after the yield point which we attributed to the delaying of strain localization by EPR reinforcement. Friction had a significant effect on the yield behavior as well as on the post yield behavior of the materials, showing a significant difference between the true stress-strain curves of the two thicknesses of specimen. Moreover, the thicker specimens of neat PP and PP-Nanocor had an important failure mode during dynamic testing at room temperature and without lubrication due to the barreling induced crack that propagated in the specimen and led to the formation of a peripheral fragment. Although the friction effect on the yield behavior of the neat PP and PP-Nanocor can be reduced by using petroleum jelly, the lubrication effect was limited to their post yield behaviors, particularly for room temperature testing and with a thick specimen.

Acknowledgments The authors would like to acknowledge the Alsace Region for the financial support. The authors also acknowledge the Fond National de la Recherche (FNR) of Luxembourg for the PhD Grant of Dr. Kui Wang.

\section{References}

1. Gray GT (2000) Classic split-Hopkinson pressure bar testing. Mechanical testing and evaluation, vol 8. ASM International, Materials Park, pp 462-476

2. Gray GT, Blumenthal WR (2000) Split-Hopkinson pressure bar testing of soft materials. Mechanical Testing and Evaluation, vol 8. ASM International, Materials Park, pp 488-496

3. Briscoe BJ, Nosker RW (1984) The influence of interfacial friction on the deformation of high density polyethylene in a split hopkinson pressure bar. Wear 95(3):241-262. doi:10.1016/00431648(84)90140-6

4. Song B, Chen W, Montgomery ST, Forrestal MJ (2009) Mechanical response of an alumina-filled epoxy at various strain rates. J Compos Mater 43(14):1519-1536. doi:10.1177/002199 8308337741

5. Ramesh KT, Narasimhan S (1996) Finite deformations and the dynamic measurement of radial strains in compression Kolsky bar experiments. Int J Solids Struct 33(25):3723-3738. doi:10. 1016/0020-7683(95)00206-5

6. Lu YB, Li QM (2011) Dynamic behaviour of polymers at high strain-rates based on split Hopkinson pressure bar tests. Int $\mathbf{J}$ Impact Eng 38(1):41-50. doi:10.1016/j.ijimpeng.2010.08.001 
7. Rietsch F, Bouette B (1990) The compression yield behaviour of polycarbonate over a wide range of strain rates and temperatures. Eur Polym J 26(10):1071-1075. doi:10.1016/0014-3057(90) 90005-O

8. Guo Y, Li Y (2007) Quasi-static/dynamic response of $\mathrm{SiO}_{2-}$ epoxy nanocomposites. Mat Sci Eng A Struct 458(1-2):330-335. doi:10.1016/j.msea.2007.02.011

9. Furmanski J, Brown EN, Clements B, Cady CM, Gray GT (2012) Large-strain time-temperature equivalence in high density polyethylene for prediction of extreme deformation and damage. EPJ Web Conf 26:01057. doi:10.1051/epjconf/20122601057

10. Lee OS, Kim MS (2003) Dynamic material property characterization by using split Hopkinson pressure bar (SHPB) technique. Nucl Eng Des 226(2):119-125. doi:10.1016/s0029-5493(03) 00189-4

11. Segreti M, Rusinek A, Klepaczko JR (2004) Experimental study on puncture of PMMA at low and high velocities, effect on the failure mode. Polym Test 23(6):703-718. doi:10.1016/j.poly mertesting.2004.01.005

12. Wang K, Boumbimba RM, Bahlouli N, Ahzi S, Muller R, Bouquey M (2012) Dynamic behaviour of a melt mixing polypropylene organoclay nanocomposites. J Eng Mater Technol 134(1):010905. doi:10.1115/1.4005420

13. Wang K, Addiego F, Laachachi A, Kaouache B, Bahlouli N, Toniazzo V, Ruch D (2014) Dynamic behavior and flame retardancy of HDPE/hemp short fiber composites: effect of coupling agent and fiber loading. Compos Struct 113:74-82. doi:10.1016/j. compstruct.2014.03.009

14. Wang K, Addiego F, Bahlouli N, Ahzi S, Rémond Y, Toniazzo V (2014) Impact response of recycled polypropylene-based composites under a wide range of temperature: effect of filler content and recycling. Compos Sci Technol 95:89-99. doi:10.1016/j. compscitech.2014.02.014

15. Matadi R, Hablot E, Wang K, Bahlouli N, Ahzi S, Avérous L (2011) High strain rate behaviour of renewable biocomposites based on dimer fatty acid polyamides and cellulose fibres. Compos Sci Technol 71(5):674-682. doi:10.1016/j.compscitech. 2011.01.010

16. Pessey D, Bahlouli N, Pattofatto S, Ahzi S (2008) Polymer composites for the automotive industry: characterisation of the recycling effect on the strain rate sensitivity. Int J Crashworthines 13(4):411-424. doi:10.1080/13588260802030745

17. Patlazhan S, Remond Y (2012) Structural mechanics of semicrystalline polymers prior to the yield point: a review. J Mater Sci 47(19):6749-6767. doi:10.1007/s10853-012-6620-y

18. Wang K, Brüster B, Addiego F, Kfoury G, Hassouna F, Ruch D, Raquez JM, Dubois P (2015) Strain-induced deformation mechanisms of polylactide plasticized with acrylated poly (ethylene glycol) obtained by reactive extrusion. Polym Int 64(11): 1544-1554. doi:10.1002/pi.4927

19. Dioh NN, Leevers PS, Williams JG (1993) Thickness effects in split Hopkinson pressure bar tests. Polymer 34(20):4230-4234. doi:10.1016/0032-3861(93)90181-9

20. Dioh NN, Ivankovic A, Leevers PS, Williams JG (1994) The high strain rate behaviour of polymers. J Phys IV 4(8):119. doi:10. 1051/jp4:1994818

21. Song B, Chen W (2004) Dynamic stress equilibration in split Hopkinson pressure bar tests on soft materials. Exp Mech 44(3):300-312. doi:10.1007/bf02427897

22. Trautmann A, Siviour CR, Walley SM, Field JE (2005) Lubrication of polycarbonate at cryogenic temperatures in the split Hopkinson pressure bar. Int J Impact Eng 31(5):523-544. doi:10. 1016/j.ijimpeng.2004.02.007

23. Lee OS, Kim GH (2000) Thickness effects on mechanical behavior of a composite material(1001P) and polycarbonate in split Hopkinson pressure bar technique. J Mater Sci Lett 19(20):1805-1808. doi:10.1023/a:1006786122575

24. Walley S, Field J (1994) Strain rate sensitivity of polymers in compression from low to high rates. DYMAT J 1(3):211-227

25. Benaceur I, Othman R, Guegan P, Dhieb A, Damek F (2008) Sensitivity of the flow stress of Nylon 6 and Nylon 66 to strainrate. Int J Mod Phys B 22 (09n11):1249-1254. doi:10.1142/ S021797920804661X

26. Walley SM, Field JE, Pope PH, Safford NA (1989) A study of the rapid deformation behaviour of a range of polymers. Philos Trans R Soc Lond A Math Phys Sci 328(1597):1-33. doi:10.1098/rsta. 1989.0020

27. Instruction manual of David, SHPB tests analysis software, Labview version 10041, https://www.sites.google.com/site/hop kinsonbars/home/david

28. Ravichandran G, Subhash G (1994) Critical appraisal of limiting strain rates for compression testing of ceramics in a split hopkinson pressure bar. J Am Ceram Soc 77(1):263-267. doi:10. 1111/j.1151-2916.1994.tb06987.x

29. Zhao H, Gary G (1996) On the use of SHPB techniques to determine the dynamic behavior of materials in the range of small strains. Int J Solids Struct 33(23):3363-3375. doi:10.1016/00207683(95)00186-7

30. Malinowski JZ, Klepaczko JR (1986) A unified analytic and numerical approach to specimen behaviour in the Split-Hopkinson pressure bar. Int J Mech Sci 28(6):381-391. doi:10.1016/ 0020-7403(86)90057-3

31. Bertholf LD, Karnes CH (1975) Two-dimensional analysis of the split hopkinson pressure bar system. J Mech Phys Solids 23(1):1-19. doi:10.1016/0022-5096(75)90008-3

32. Zhao H (1998) A study of specimen thickness effects in the impact tests on polymers by numeric simulations. Polymer 39(5):1103-1106. doi:10.1016/s0032-3861(97)00374-1

33. Buckley CP, Harding J, Hou JP, Ruiz C, Trojanowski A (2001) Deformation of thermosetting resins at impact rates of strain. Part I: experimental study. J Mech Phys Solids 49(7):1517-1538. doi:10.1016/s0022-5096(00)00085-5

34. Lee O, Kim D, Han Y, Park Y (2008) Dynamic deformation of hot temperature degraded POM and PP using a modified SHPB with pulse shaper technique. J Mech Sci Technol 22(9): 1692-1698. doi:10.1007/s12206-008-0616-1

35. Dharan C, Hauser F (1970) Determination of stress-strain characteristics at very high strain rates. Exp Mech 10(9):370-376. doi:10.1007/bf02320419

36. Gorham DA (1989) Specimen inertia in high strain-rate compression. J Phys D Appl Phys 22(12):1888. doi:10.1088/00223727/22/12/014

37. Davies EDH, Hunter SC (1963) The dynamic compression testing of solids by the method of the split Hopkinson pressure bar. J Mech Phys Solids 11(3):155-179. doi:10.1016/0022-5096(63)90050-4

38. Walley SM, Field JE, Pope R, Safford NA (1991) The rapid deformation behaviour of various polymers. J Phys III France 1(12):1889-1925. doi:10.1051/jp3:1991240

39. Hartley RS, Cloete TJ, Nurick GN (2007) An experimental assessment of friction effects in the split Hopkinson pressure bar using the ring compression test. Int $\mathbf{J}$ Impact Eng 34(10):1705-1728. doi:10.1016/j.ijimpeng.2006.09.003

40. Siviour CR, Walley SM, Proud WG, Field JE (2005) The high strain rate compressive behaviour of polycarbonate and polyvinylidene difluoride. Polymer 46(26):12546-12555. doi:10. 1016/j.polymer.2005.10.109

41. Gray GT, Blumenthal WR, Trujillo CP, Carpenter RW (1997) Influence of temperature and strain rate on the mechanical behavior of Adiprene L-100. J Phys IV France 7(3):523. doi:10. 1051/jp4:1997390 
42. Wang K, Bahlouli N, Addiego F, Ahzi S, Rémond Y, Ruch D, Muller R (2013) Effect of talc content on the degradation of reextruded polypropylene/talc composites. Polym Degrad Stab 98(7):1275-1286. doi:10.1016/j.polymdegradstab.2013.04.006

43. Bahlouli N, Pessey D, Raveyre C, Guillet J, Ahzi S, Dahoun A, Hiver JM (2012) Recycling effects on the rheological and thermomechanical properties of polypropylene-based composites. Mater Des 33:451-458. doi:10.1016/j.matdes.2011.04.049

44. Wang K, Ahzi S, Matadi Boumbimba R, Bahlouli N, Addiego F, Rémond Y (2013) Micromechanical modeling of the elastic behavior of polypropylene based organoclay nanocomposites under a wide range of temperatures and strain rates/frequencies. Mech Mater 64:56-68. doi:10.1016/j.mechmat.2013.04.009

45. Zebarjad SM, Bagheri R, Reihani SMS, Lazzeri A (2003) Deformation, yield and fracture of elastomer-modified polypropylene. J Appl Polym Sci 90(14):3767-3779. doi:10.1002/app. 12955

46. Okereke MI, Buckley CP, Siviour CR (2012) Compression of polypropylene across a wide range of strain rates. Mech Time Depend Mater 16(4):361-379. doi:10.1007/s11043-012-9167-z

47. Rodríguez-Martínez JA, Rusinek A, Arias A (2009) Relation between strain hardening of steel and critical impact velocity in tension. J Theor App Mech 47(3):645-665

48. Rosenberg Z, Ashuach Y, Kreif R (2010) The effect of specimen dimensions on the propensity to adiabatic shear failure in Kolsky bar experiments. Matéria (Rio de Janeiro) 15:283-290. doi:10. 1590/S1517-70762010000200028

49. Furmanski J, Cady CM, Brown EN (2013) Time-temperature equivalence and adiabatic heating at large strains in high density polyethylene and ultrahigh molecular weight polyethylene. Polymer 54(1):381-390. doi:10.1016/j.polymer.2012.11.010

50. Chou S, Robertson K, Rainey J (1973) The effect of strain rate and heat developed during deformation on the stress-strain curve of plastics. Exp Mech 13(10):422-432. doi:10.1007/BF02324886
51. Rittel D (1999) On the conversion of plastic work to heat during high strain rate deformation of glassy polymers. Mech Mater 31(2):131-139. doi:10.1016/s0167-6636(98)00063-5

52. Garg M, Mulliken AD, Boyce MC (2008) Temperature rise in polymeric materials during high rate deformation. J Appl Mech 75(1):011008-011009. doi:10.1115/1.2745388

53. Dodd B, Bai Y (2012) Adiabatic shear localization: frontiers and advances. Elsevier Limited, Oxford

54. Williamson DM, Siviour CR, Proud WG, Palmer SJP, Govier R, Ellis K, Blackwell P, Leppard C (2008) Temperature-time response of a polymer bonded explosive in compression (EDC37). J Phys D Appl Phys 41(8):085404

55. Inberg JPF (2001) Fracture of polycarbonate/ABS blends. University of Twente, Enschede

56. Zebarjad SM, Lazzeri A, Bagheri R, Reihani SMS, Frounchi M (2003) Fracture mechanism under dynamic loading of elastomermodified polypropylene. Mater Lett 57(18):2733-2741. doi:10. $1016 / \mathrm{s} 0167-577 \mathrm{x}(02) 01367-8$

57. Hall IW, Guden M (2003) Split Hopkinson Pressure Bar compression testing of an aluminum alloy: effect of lubricant type. J Mater Sci Lett 22(21):1533-1535. doi:10.1023/a:1026167517837

58. Siebel E (1923) Grundlagen zur Berechnung des Kraft und Arbeitbedorf bei Schmieden und Walzen. Stahl Eisen 43:1295

59. Gong F, Guo B, Wang C, Shan D (2010) Size effect on friction of C3602 in cylinder compression. Tribol T 53(2):244-248. doi:10. 1080/10402000903226358

60. Kudo H, Aoi K (1967) Effect of compression test condition upon fracturing of a medium carbon steel. J Jpn Soc Technol Plast 18:17-27

61. Dodd B, Bai Y (1987) Ductile fracture and ductility: with applications to metalworking. Academic Press, London

62. Collyer AA (1994) Rubber toughened engineering plastics. Springer. doi:10.1007/978-94-011-1260-4 